\title{
Finos Fios, Renda de Agulha... \\ Uma Alternativa de Trabalho, Múltiplos Olhares para a Qualidade
}

http://dx.doi.org/10.21527/2237-6453.2019.49.209-221

Recebido em: 6/6/2018

Aceito em: 28/5/2019

\author{
Rogério Zanon da Silveira ${ }^{1}$, Ana Claudia Borges Campos², \\ Marcelo Calderari Miguel ${ }^{3}$
}

\begin{abstract}
RESUMO
Este artigo enfatiza o trabalho desenvolvido pelas rendeiras de Divina Pastora, município localizado na mesorregião do leste sergipano, na microrregião do Cotinguiba, região turística "Polo dos Tabuleiros", tendo como destaque a produção de renda irlandesa, produto do ecoturismo. O objetivo desta pesquisa é avaliar a satisfação dos compradores de renda irlandesa em relação à qualidade dos serviços prestados pelas artesãs que comercializam e produzem os bordados - um elemento cultural central da identidade local. A metodologia deste estudo possui caráter descritivo, quantitativo e qualitativo e adaptativo da abordagem métrica-metodológica Servqual. Os resultados obtidos sugerem que os atributos da qualidade são delineados primordialmente pelos construtos tangíveis e empáticos. Ao final, são discutidas implicações comerciais, acadêmicas e socioculturais que cingem o contexto do Patrimônio Cultural e a arte de saber-fazer das mulheres artífices na região pesquisada.
\end{abstract}

Palavras-chave: Artesanato. Mulheres. Patrimônio cultural. Avaliação da qualidade. Servqual.

\section{THIN THREAD, NEEDLE WORKMANSHIP... A WORK ALTERNATIVE, MULTIPLE LOOKS ON QUALITY}

\begin{abstract}
This article emphasizes the work done by the renters of Divina Pastora, a municipality located in the eastern Sergipano mesoregion, in the Cotinguiba microregion, a tourist region called 'Polo dos Tabuleiros', with an emphasis on the Irish income produced by Ecotourism. The objective of this research is to evaluate the satisfaction of Irish Income buyers in relation to the quality of services provided by artisans who market and produce embroidery - a central cultural element of local identity. The methodology of this study is descriptive, quantitative and qualitative and adaptive of the metric-methodological approach Servqual. The results obtained suggest that the quality attributes are delineated primarily by the tangible and empathic constructs. At the end, commercial, academic and socio-cultural implications are discussed, encompassing the context of Cultural Heritage and the art of know-how of women artisans in the region surveyed.
\end{abstract}

Keywords: Crafts. Women. Cultural heritage. Quality assessment. Servqual.

\footnotetext{
${ }^{1}$ Doutor em Administração pela Universidade Federal de Minas Gerais (UFMG). Professor da Universidade Federal do Espírito Santo (Ufes). rogerio.silveira@ufes.br

${ }^{2}$ Doutora em Ciências da Informação pela Universidade de Brasília (UNB). Professora da Universidade Federal do Espírito Santo (Ufes). ana.c.campos@ufes.br

${ }^{3}$ Graduado em Administração pela Universidade Federal do Espírito Santo (Ufes). Servidor da Caixa Econômica Federal (CEF). calderari100@gmail.com
} 


\section{VISIBILIDADE DAS BORDADEIRAS DE DIVINA PASTORA: Experiências e Avaliação de Serviços, Coisas e Cenas da Vida}

No Brasil, o processo de criação de rendas ostenta inovação, reelaboração e ressignificação do fazer artístico tradicional, mesmo atendendo a uma forte demanda do mercado consumidor. Nesse sentido, busca-se compreender o modo de fazer renda e a qualidade do atendimento, com um olhar humano no itinerário dessas mulheres artesãs, sua sabedoria e prática (MASCELANI, 2008, p. 36-39). Como expõe Mascelani (2008, p. 140), "lançar-se no cosmos das artes e do artesanato é inventar outras formas de discurso, outros léxicos, arquitetar caminhos, cruzar veredas".

Segundo Mauss (2003), as pessoas constituem-se não apenas pelo biológico, pelo psíquico e pelo social, mas, também, no e pelo que fazem, de acordo com seus conceitos de fator social total. Se a pessoa falar de todas as suas características, mas não disser qual a atividade produtiva que desenvolve na sociedade, o seu interlocutor não consegue identificá-la no estrato social e continuará seu desejo de saber o que essa pessoa faz.

Em linha de pensamento parecida, Weber (2004) demonstrou, em seus estudos, que o trabalho, o fazer no dia a dia, é o que caracteriza a identidade e a personalidade do ser humano, que concede seu status social e que o localiza no estrato social. As mulheres rendeiras, pela sua produção de rendas, adquirindo autonomia financeira entre outros aspectos culturais, passaram a ter o status de artesãs e trabalhadoras, em virtude da valorização da atividade produtiva na contemporaneidade. Enfim, essa transformação permitiu a esse conjunto de mulheres migrar do status de domésticas (do lar) para o status de artesãs (trabalhadoras).

Elas executam processos concretos de fazer rendas irlandesas, mas não possuem uma rotina característica do ambiente de fábrica. Numa parte do seu dia, elas se dedicam à família e às atividades domésticas, numa dupla jornada, caráter tão peculiar a tantas outras mulheres brasileiras. Em outro horário, geralmente comum a todas elas, ficam centradas no modo de fazer renda irlandesa. Vivem realidades pluriversas: o universo da família e um outro universo no qual tecem relações sociais com outras rendeiras, em que, para além da questão financeira, elas se divertem, criam amizades duradouras e se distraem, enfim, enfrentam atividades que passam também a ser consideradas uma espécie de lazer (SOARES, 2011, p. 71-72).

No universo dessas mulheres, tudo é embaralhado: o ganho econômico, as tarefas domésticas, o cuidado da família, o lazer, nesse movimento no qual nada é, mas em que tudo há, quando as relações são mais importantes que os indivíduos de forma isolada. Seu modo de fazer é diário, cotidiano (SOARES, 2011). Assim, a rendeira integra "o imaginário popular brasileiro como artesã de um ofício tecido em finos fios, como guardiã da memória coletiva [...] cuja importância econômica brinca com os sentidos da própria palavra [...] renda (ofício) [e] renda (rendimento/valor financeiro)" (MELLO; SILVA, 2014, p. 132).

O município de Divina Pastora nasceu de um povoado chamado Ladeira, onde surgiu a devoção a Nossa Senhora Divina Pastora, uma contribuição marcante dos frades missionários provenientes de Sevilha, na Espanha. O nome Divina Pastora originou-se no município em razão de uma crença na aparição de Nossa Senhora naquele local em 8 
de setembro de 1703. A história relata que ela apareceu vestida como pastora sentada numa rocha, onde pastavam ovelhas, simbolizando a pastora que cuida de seu rebanho e mãe que cuida de seus filhos.

A cidade de Divina Pastora destaca-se na produção desse artesanato. As mulheres daquela região criaram, em 1998, a Associação para o Desenvolvimento da Renda de Divina Pastora (Asderen). A Asderen possui sede própria e, no ano de 2000, já contava com 122 artesãs associadas. Essas mulheres já ganharam duas vezes o Top100 do Sebrae e já possuem o selo de Indicação Geográfica do Instituto Nacional de Propriedade Industrial e Intelectual (Inpi).

Esse contexto tem sido objeto de nosso interesse de pesquisa, materializado em trabalhos já publicados em periódicos nacionais, e o que aguçou nossa vontade e iniciativa pela realização deste estudo, com o qual se busca alcançar o seguinte objetivo: compreender as expectativas e percepções do público comprador de rendas irlandesas quanto ao serviço prestado pelas mulheres bordadeiras, que produzem e atendem no município sergipano de Divina Pastora, região turística "Polo dos Tabuleiros". A busca por esse objetivo dá-se por meio do uso do modelo Servqual (Service Quality Gap Analysis), numa abordagem metodológica preponderantemente quantitativa.

Este trabalho justifica-se pela relevância das discussões em torno da produção de renda irlandesa (reconhecido patrimônio cultural) e pela atuação das mulheres nesse processo comercial que envolve territorialidade e "empoderamento" feminino. Em 27 de novembro de 2008, o modo de fazer renda irlandesa foi registrado pelo Instituto do Patrimônio Histórico e Artístico Nacional (Iphan) como Patrimônio Imaterial no livro de Registro dos Saberes. Este fato histórico é um estímulo para que os gestores públicos sergipanos valorizem esse ícone cultural estadual e proporcionem melhores condições mercadológicas para que essas artesãs, além de compartilharem saberes e técnicas, possam usufruir de maior autonomia econômica em suas famílias (MARTINS; ALMEIDA, 2010).

A relevância desta pesquisa reside nas dimensões acadêmicas, científicas e sociais que alcança. Ao dirigirmos o olhar para a árdua empreitada das mulheres artesãs (bordadeiras) e de sua atuação no município de Divina Pastora, levamos em conta as seguintes esferas para diagnósticos:

a) acadêmica: amplia o entendimento sobre o processo de desenvolvimento de serviços, articulada à apreciação de um potencial de uma região turística, comercial e religiosa que influencia o "saber-fazer" da bordadeira, da artesã, da empreendedora: da mulher;

b) científica: visa a contribuir como mais uma fonte de conhecimento sobre a qualidade da recepção, hospitalidade e sobre o processo criativo feminino na região estudada;

c) social: subsidia as tomadas de decisão com base nos resultados obtidos, possibilitando desencadear ações (governamentais, associativas, entre outras) para a visibilidade da produção artística e cultural das mulheres, bem como premiar a gestão, historicidade e inovação que repassa o ofício artesão. 
Neste artigo esperamos contribuir para a visibilidade de estudos do saber e do fazer artesanal no município estudado, núcleo de criação e de esforço mercadológico, que antecipa, estimula e cativa o processo de desenvolvimento de serviços e é aprimorado pelas mãos femininas, agentes desse processo transformador e reverenciado.

\section{TRABALHO, DESENVOLVIMENTO E AGIR FEMININO}

\section{Novos Patamares, Sociabilidades e Tessituras Latentes}

O debate sobre gênero adquire evidência na "vitrine" do mercado de trabalho quando a mulher se torna uma competidora na disputa pelo emprego, posto que a participação no espaço público do trabalho condiciona ao ser feminino uma força de qualificação alternativa. Além da clássica luta pela emancipação das mulheres em relação ao sistema patriarcal, as forças femininas aspiram a liberdade de emancipar-se por meio do trabalho, e isso foi "amadurecendo à medida que elementos femininos foram entrando em áreas exclusivas do homem (trabalho fora do lar, educação, participação da vida social)" (OURIQUES; RAMOS, 2006, p. 156).

Esses mesmos autores destacam que a valorização do trabalho se atrela cada vez mais aos conteúdos mercadológicos, em que a mulher prefere ser reconhecida pelo trabalho fora de casa, não interrogando o valor que seu trabalho na esfera doméstica expressa ao sistema capitalista de produção. Cabe observar que, nas camadas sociais mais baixas, o trabalho nunca esteve ausente e o sustento do lar, muitas vezes, provém da atuação das mulheres. A "mudança na configuração do mercado de trabalho" é uma frase modesta, entretanto de fátua reflexão (até mesmo de inflexão) e resume o pensamento de Ouriques e Ramos (2006) em torno da estruturação capitalista.

Cotidiano de várias mulheres, entrelaçadas nos fios e lacês de seus bordados, essas mulheres, algumas senhoras na terceira idade e outras muito jovens - muitas matriarcas de suas famílias -, buscam o mercado para o atendimento das demandas de consumo estético de outrem, mas também para o provimento de sua sustentabilidade.

A inclusão socioeconômica dessas mulheres na lógica de mercado pressupõe uma série de medidas que agregue valor e qualidade tanto ao produto que é fruto de seu trabalho, como nas relações de atração do consumidor, negociação e fidelização. Para além de um "fetichismo do objeto patrimonializado", ao relacionar cultura e economia tornando-a um meio de sobrevivência, incentiva-se a continuidade do ofício, das histórias de vida e a transmissão do savoir faire de cada artesã para as futuras gerações (MELLO; SILVA, 2014, p. 141-143).

Ouriques e Ramos (2006) reportam que a nova ordem denominada neoliberal lesiona a arquitetura de empregos e desmorona e fragmenta as relações sociais, e, assim, deflagra uma crise potencial no mercado. Tal fragmentação se dá em razão de o mecanismo de compra e venda consistir em forma de aquisição de bens e serviços necessários à sobrevivência do ser humano.

Mudanças significativas no mercado de trabalho brasileiro, redução de impostos e ampliação do desemprego, insurgem pela onda que a estruturação capitalista provocou no Brasil, que torna precário, cada vez mais, o painel das relações trabalhistas. Igualmente, observa-se que no setor público brasileiro, responsável pela geração de 
empregos ao lado do setor privado, vem sendo limitada gradativamente sua capacidade empregadora (OURIQUES; RAMOS, 2006), ampliando a situação desfavorável no mercado de trabalho hodierno. Para enfrentar esse contexto, os preceitos-pontes da Agenda 2030 de Desenvolvimento Sustentável, elencam 17 objetivos globais com 169 metas globais, tendo como foco as pessoas, as parcerias, a prosperidade, o planeta e a paz mundial.

Essas diretrizes definidas pela Organização das Nações Unidas (ONU) em 2015, ressaltam, para fins desta pesquisa, a questão da igualdade de gênero e o empoderamento das mulheres e meninas no quinto Objetivo de Desenvolvimento Sustentável (ODS). Evidencia-se também, no oitavo ODS, a necessidade de se promover o crescimento econômico sustentável e inclusivo, o pleno emprego e o trabalho decente para todos (BRASIL, 2016).

\section{AUTONOMIA, CULTURA, SUSTENTABILIDADE, SABERES...: As Rendeiras de Divina Pastora}

“O próximo dia 7 de abril de 2018 marcará uma nova fase de produção da renda irlandesa produzida em Sergipe" (IPHAN, 2018, p. 1). Com esse anúncio, o portal do Instituto do Patrimônio Histórico e Artístico Nacional (Iphan) divulgava uma nova fase no trabalho das rendeiras dos núcleos das localidades de Divina Pastora, Laranjeiras, Maruim e Nossa Senhora do Socorro. Por meio do Ipham, as mulheres rendeiras dessa região ganhariam autonomia na fabricação do lacê, uma matéria-prima utilizada na produção de renda, cujos processos de produção e o próprio produto são considerados Patrimônio Cultural do Brasil desde o ano de 2009.

$\mathrm{Na}$ oportunidade, foram doadas nove máquinas compradas pelo Instituto para as associações e cooperativas das rendeiras desses quatro núcleos, além da promoção de treinamento para a operacionalização das máquinas que fabrica o lacê. A renda irlandesa é um dos produtos artesanais mais destacados no Estado de Sergipe, principalmente a renda produzida na localidade de Divina Pastora, e o lacê passou a ser uma marca específica dessa produção. A renda Irlandesa tem como matéria-prima essencial o lacê, cordão flexível, achatado e sedoso, que tinha como único fornecedor uma fábrica no Rio de Janeiro (RJ).

O técnico do Iphan, Eric Ferreira Souza, explica que o lacê tem para as rendeiras um significado "muito forte, sendo o diferencial da sua renda tanto no sentido da produção, quanto na distinção dos trabalhos produzidos em outras regiões do Brasil. A busca pela matéria-prima exigiu muita dedicação do Iphan, e o resultado de salvaguarda foi melhor que o esperado" (IPHAN, 2018, p. 1).

Constitui-se de saberes tradicionais que foram re-significados pelas rendeiras do interior sergipano a partir de fazeres seculares, que remontam à Europa do século $\mathrm{XVII}$, e são associados à própria condição feminina na sociedade brasileira, desde o período colonial até a atualidade. Trata-se de uma renda de agulha que tem como suporte o lacê, cordão brilhoso que, preso a um debuxo ou risco de desenho sinuoso, deixa espaços vazios a serem preenchidos pelos pontos. Estes pontos são bordados compondo a trama da renda com motivos tradicionais e ícones da cultura brasileira, criados e recriados pelas rendeiras (IPHAN, 2018, p. 1). 
Segundo informações divulgadas pelo Iphan (IPHAN, 2018), a renda irlandesa para as rendeiras dessas localidades constitui fonte de recurso econômico, cultural, social e educacional inestimável. A referência de se fazer esse tipo de renda tem origem no município de Divina Pastora e está associado ao universo feminino, mas originalmente vinculado à aristocracia. Após os anos 50 do século 20, a confecção de renda surge como alternativa de trabalho, ocupando atualmente mais de centenas de artesãs (ZACCHI; FIGUEIREDO, 2013), além de consistir em referência cultural (expressão simbólica e material) ímpar no Estado de Sergipe.

Desse modo, é possível perceber que são as relações entre o campo político e o campo do patrimônio, no qual se inclui uma pluralidade de sujeitos organizados em movimentos, redes, e associações, que irão conformar a preservação de determinados bens culturais. [...] hoje, uma pluralidade de sujeitos interferem e participam ativamente do debate e da luta em prol dos seus patrimônios e de suas memórias (POSSAMAI, 2018, p. 42).

O modo de fazer renda irlandesa, tendo como referência este ofício em Divina Pastora foi inscrito no Livro de Registro dos Saberes do Iphan em 2009, livro em que são registrados Bens Culturais Imateriais oriundos de todas as partes do Brasil.

Para melhor utilização do Programa Regional de Desenvolvimento do Turismo (PRODETUR Nordeste), a Secretaria Estadual de Turismo de Sergipe dividiu o Estado em cinco polos. Um desses polos - o Polo dos Tabuleiros em Sergipe - é formado pelos municípios de Carmópolis, Divina Pastora, Japaratuba, Maruim e Nossa Senhora das Dores, em que se destaca a produção de renda pelas mulheres, notadamente a renda irlandesa. Os primeiros registros da renda irlandesa são encontrados no século 15 , criação das artesãs medievais italianas que repassaram o modo de produção às missionárias da Irlanda, que, por sua vez, vieram ao Brasil e ensinaram a técnica no município de Divina Pastora (SE).

\section{TRAJETO METODOLÓGICO}

Esta pesquisa é de natureza quantitativa, complementada por informações abordadas de forma qualitativa. A técnica de coleta de dados envolveu a aplicação de questionário semiestruturado com alternativas de resposta dispostas em escala de cinco pontos do tipo Likert. A Escala Likert é uma estrutura psicométrica usada em estudos quantitativos para avaliar o nível de discordância ou concordância (LIKERT, 1932).

Usualmente são empregados cinco níveis de respostas, quando os respondentes marcam uma alternativa entre 1 e 5 da escala Likert (sendo $1=$ menos pertinente e 5 = muito pertinente) para os 22 pares de itens (importância $x$ satisfação). A escala tipo Likert exige resposta graduada para cada afirmação e, geralmente, esses níveis servem para mostrar os extremos, considerando que o ponto intermediário (indicativo 3) representa a indecisão, apatia ou neutralidade.

Vieira e Dalmoro (2008, p. 1), em pesquisa sobre a construção de escalas tipo Likert, expuseram que, desde a introdução do método da escala por Rensis Likert em 1932, "diversos estudos, provindos de diversas áreas como psicologia, educação e 
marketing têm investigado as implicações do uso de diferentes formatos de escalas tipo Likert". A que se mostra mais adequada, no entanto, é a de cinco pontos, por permitir velocidade na resposta e também confiabilidade.

A operacionalização do modelo descrito serve de base para a mensuração da qualidade em serviços. A partir de um olhar dos pesquisadores Parasuraman, Zeithaml e Berry (1985), a diferença entre as pontuações sinalizam que há lacunas (gaps) entre o que se espera e o real desempenho do serviço. Surge, assim, uma forma pioneira de averiguar o enfoque da qualidade com forma métrica e conceitual, posto que o modelo é designado Servqual (Análise das Lacunas na Qualidade dos Serviços).

A abordagem Servqual baseia-se na comparação entre a expectativa/importância de um serviço e a constatação da percepção/satisfação do respondente que utilizou o serviço. A resultante mostra a possibilidade de um hiato em torno de cinco dimensões, que são as determinantes confiabilidade, garantia (ou segurança), tangibilidade, empatia e receptividade. Sobre esses construtos da qualidade, Las Casas (2017) reporta que:

a) Confiabilidade - é importante para prestar serviços de qualidade, gerada pela habilidade de fornecer o que foi prometido de forma segura e precisa.

b) Segurança - os consumidores querem dos prestadores de serviços a habilidade de transmitir segurança e confiança caracterizada pelo conhecimento e cortesia dos funcionários.

c) Aspectos tangíveis - os aspectos físicos que circundam a atividade de prestação de serviços também têm sua importância como fator de influência [...] as instalações, equipamentos e aparência dos funcionários.

d) Empatia - grau de cuidado e atenção pessoal dispensados pelos clientes. Também é importante aspecto a capacidade de se colocar no lugar dos outros.

e) Receptividade - é a disposição de ajudar os clientes e fornecer serviços com presteza (LAS CASAS, 2017, p. 67).

O critério para seleção da comunidade pesquisada levou em conta a representatividade dessa região, disponibilidade das artesãs e a movimentação da localidade pelo festejo religioso, características que constituem situações sine qua non para o empreendimento "mercatoetnográfico". A população-alvo foi constituída pelos turistas/visitantes, compradores de artefatos de renda irlandesas, atendidos pelas bordadeiras (muIheres artesãs) que produzem e comercializam as peças no município de Divina Pastora. A amostra selecionada é não probabilística acidental (por conveniência), reunindo 66 clientes que representam os respondentes dessa avaliação da qualidade e lacunas dos serviços.

As sentenças adotadas no presente diagnóstico certamente não representam a totalidade de atributos da qualidade dos serviços, mas, diante das pesquisas realizados por Nitecki e Hernon (2000) e Miguel e Freire (2016), verifica-se que a replicação e a adaptação da Métrica Servqual conferem traços práticos e seguros para se averiguar pontos iniciais do processo e do desenvolvimento dos serviços em foco.

O questionário semiestruturado foi aplicado no período de 11 a 21 de outubro de 2017 ao público abordado que houvesse comprado os produtos das bordadeiras, nesse período, em Divina Pastora (SE). A data escolhida foi em razão da festividade religiosa, quando ocorre a tradicional romaria com percurso de $8 \mathrm{~km}$ pela rodovia SE-160, que se inicia no município de Riachuelo e se encerra no município de Divina Pastora (SE). Tal 
evento cultural religioso (peregrinação que acontece sempre no terceiro domingo de outubro) é um dos mais expressivos do Estado de Sergipe, e envolve um quantitativo significativa de romeiros (pagadores de promessas), devotos, fiéis e turistas (visitantes, curiosos) de diversas regiões do Estado e do país.

Figura 1 - Caracterização do município de Divina Pastora

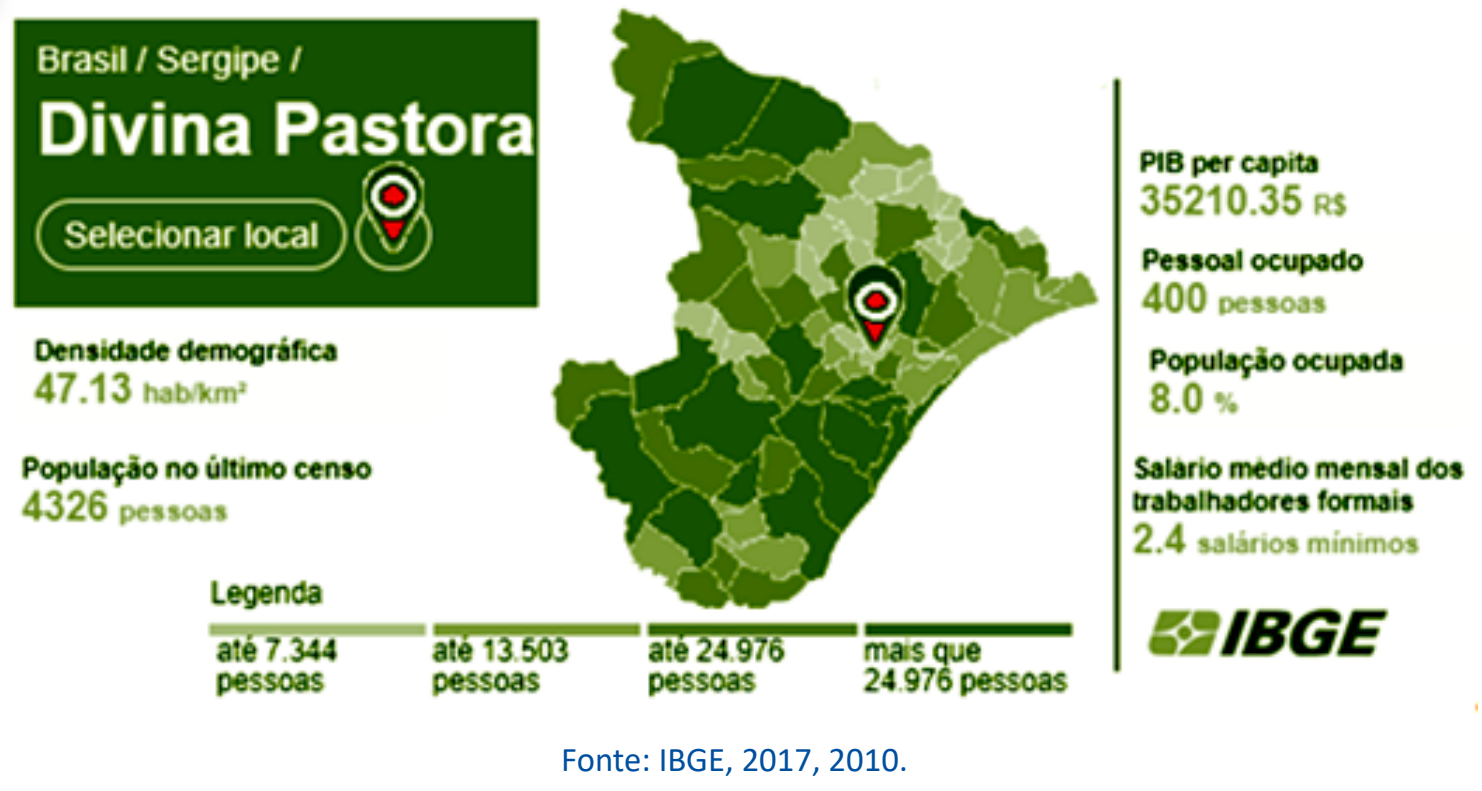

A cidade de Divina Pastora (Figura 1) não tem uma taxa expressiva de pessoas ocupadas formalmente; por conseguinte, as festividades da região e a produção de artesanato se destacam como meios para obtenção de rendas aos munícipes dessa localidade. Cabe salientar que 43 participantes (aproximadamente 65\%) desta pesquisa foram abordados nos 4 dias iniciais e, portanto, antes do fechamento do evento que envolve a celebração eucarística, mutirão de confissões e atividades inerentes à Peregrinação ao Santuário Nossa Senhora Divina Pastora.

O procedimento de coleta de dados se deu de forma aleatória conforme disponibilidade do público consumidor, durante o horário de vívida atividade comercial. $A$ participação na pesquisa ocorreu por meio de adesão espontânea, obtendo uma taxa de retorno de cerca de $20 \%$ dos entrevistados após certificação de que eram visitantes e que haviam feito contato com uma ou mais bordadeiras (estima-se cem artesãs ou mais) naquele município.

\section{APRESENTAÇÃO E ANÁLISE DOS DADOS}

Esta seção apresenta os resultados provenientes da pesquisa quantitativa. Os dados foram sintetizados e expostos em três blocos de análise, a saber: primeiramente, são apresentadas as características gerais sem pretender um estudo exaustivo; na sequência, advém o modelo básico de análise Servqual, baseado na constatação da importância e da satisfação dos respondentes; e a última subseção traz um painel qualitativo, com o resgate das opiniões sobre o ofício e os produtos das bordadeiras e interpretações que complementam a pesquisa quantitativa. 


\section{Características Gerais}

Do total de 66 respondentes, quanto ao gênero, 39 pessoas (aproximadamente $60 \%$ ) se declararam do sexo feminino e 27 (40\%) do masculino. Em termos de faixa etária, 23 (34\%) dos entrevistados tinham entre 18 e 38 anos, e os demais 43 (65\%) respondentes tinham 39 anos ou mais. Quanto à frequência de compras nessa região, 15 pessoas das entrevistadas (22\%) declararam comparecer nessa localidade rotineiramente (pelo menos uma vez no mês), 21 (31\%) respondentes reportam que frequentam semestralmente a localidade e outros $30(45 \%)$ a visitam esporadicamente (conforme demanda/negócios, festividades, tamanho de estoques).

\section{Importância e Satisfação por Dimensão Conforme a Métrica Servqual}

Para fins de estruturação do texto, os dados são apresentados tomando-se como eixos as determinantes (confiabilidade, empatia, garantia, receptividade e tangibilidade) da qualidade que caracterizam o Método Servqual (gap model).

O cálculo das lacunas (gaps) da qualidade de serviços, portanto, efetua-se pela averiguação da média dos itens comportados na dimensão do questionário, estruturado a partir de 5 dimensões e 4 assertivas por dimensão da qualidade, totalizando 22 itens avaliativos das expectativas e espelhados para a percepção dos 66 respondentes. Por exemplo, para o cálculo dos gaps da dimensão "Confiabilidade", foram somadas as médias das pontuações dos itens relativos a esta dimensão e depois divididas por quatro, ou seja, o número de questões nessa determinante.

Las Casas (2017) mostra que quando um indivíduo gosta da prestação de serviços ele dá uma nota alta; quando não gosta dá uma nota baixa. Assim sendo, para calcular as médias (importância e satisfação) as pontuações (de 1 a 5) de cada questão são somadas e depois divididas pelo número total de respondentes (66), tanto para a importância quanto para a satisfação. A seguir, calcula-se a diferença entre as duas, obtendo-se, assim, o gap por construto da qualidade (Tabela 1).

Tabela 1 - Medidas da qualidade em itens agrupados de Importância e Satisfação

\begin{tabular}{|c|c|c|c|c|c|c|c|c|c|c|c|}
\hline \multirow[t]{2}{*}{ Itens } & \multicolumn{5}{|c|}{ Importância (E) } & \multicolumn{5}{|c|}{ Satisfação (P) } & \multirow{2}{*}{$\begin{array}{l}\text { Gaps } \\
\text { P - E }\end{array}$} \\
\hline & MD & DP & CV \% & K & As & MD & DP & CV \% & K & As & \\
\hline Confiabilidade & 4,60 & 0,74 & 16,13 & 0,25 & $-0,2$ & 4,20 & 0,78 & 18,48 & 0,50 & 0,5 & $-0,40$ \\
\hline Empatia & 4,50 & 1,01 & 22,56 & 0,25 & 0,1 & 3,80 & 1,37 & 35,79 & 0,32 & 0,2 & $-0,70$ \\
\hline Garantia & 4,40 & 1,26 & 28,87 & 0,24 & 0,3 & 4,10 & 0,96 & 23,57 & 0,50 & 0,8 & $-0,30$ \\
\hline Receptividade & 4,70 & 0,45 & 9,55 & 0,50 & $-0,4$ & 3,90 & 1,41 & 36,68 & 0,25 & 0,2 & $-0,80$ \\
\hline Tangibilidade & 4,30 & 1,33 & 30,54 & 0,13 & 0,3 & 3,80 & 1,28 & 33,88 & 0,13 & 1,5 & $-0,50$ \\
\hline
\end{tabular}

Fonte: Elaborado pelos autores, dados da pesquisa (2018). 
A métrica avaliativa de importância (E) atribuída pelos respondentes, considerando as dimensões da qualidade, foi: Receptividade $(4,70)$, seguida de Confiabilidade $(4,60)$, Empatia $(4,50)$, Garantia $(4,40)$ e a menos valorizada foi a Tangibilidade $(4,30)$. Convém destacar que os aspectos tangíveis apresentam distribuição mais heterogênea de pontuação com $C V=30,54 \%$, ou seja, têm um maior coeficiente de variabilidade entre outras dimensões avaliadas.

Paralelamente, o painel (Tabela 1 ) satisfação $(P)$ mostra que a determinante mais valorizada remete à Confiabilidade $(4,20)$, seguida de Garantia $(4,10)$, Receptividade $(3,90)$ e menores resultantes advém dos aspectos tangíveis e empáticos (ambos construtos com média de 3,80).

Destaca-se, com esses dados, que quanto maior a média obtida mais homogêneo é o agrupamento médio das determinantes. Logo, o coeficiente de variabilidade mostra uma tendência de relação inversamente proporcional à média dos determinantes avaliados. Pode-se deduzir que o item com o maior Gap, na opinião dos entrevistados, foi Receptividade $(|0,80|)$, como se observa na Figura 2.

Figura 2 - Gráfico dos gaps por dimensões

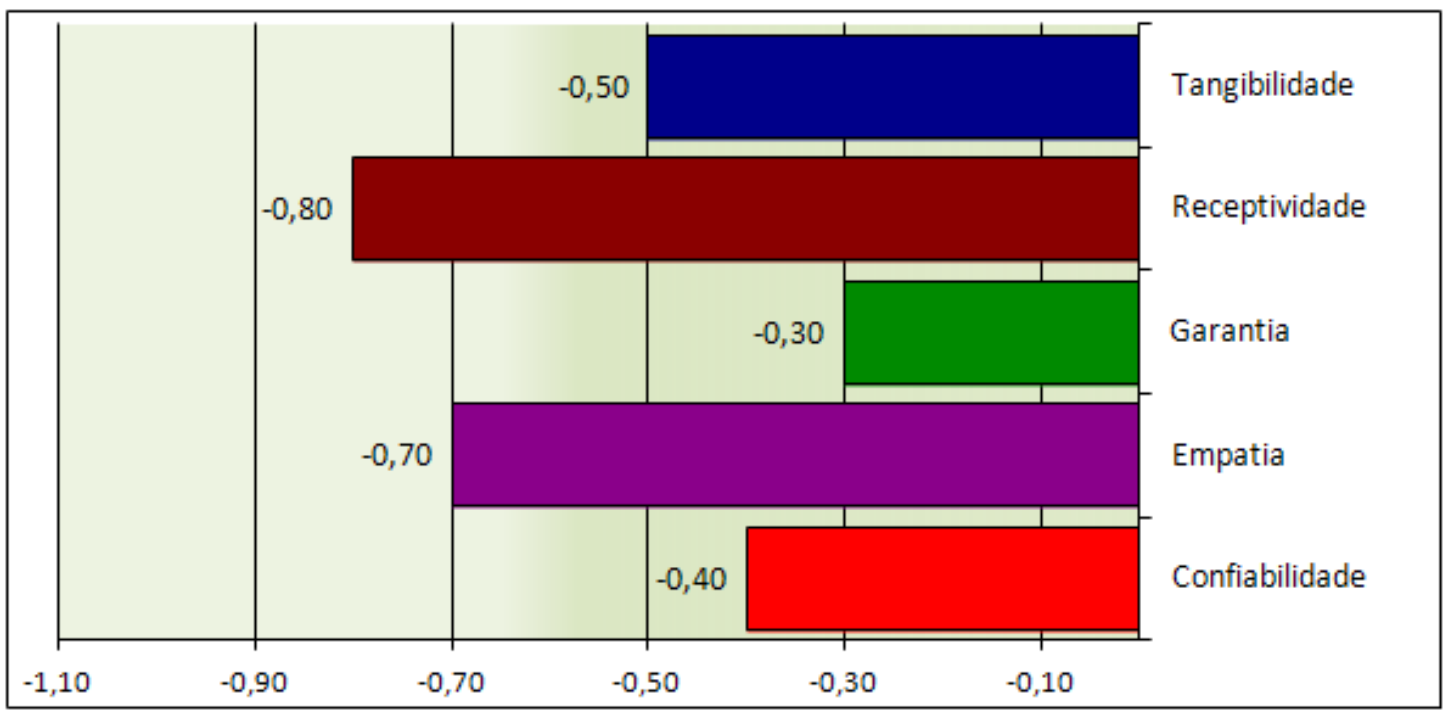

Fonte: Elaborado pelos autores, dados da pesquisa (2018).

Convêm ressaltar que as pontuações de gaps entre 0 e -1 não superam as expectativas, porém podem atender ao que os usuários realmente esperam de um serviço de qualidade (NITECKI; HERNON, 2000). Assim, pela análise da Figura 2, verifica-se que o público respondente percebe positivamente a qualidade dos serviços prestados pelas bordadeiras de Divina Pastora, bem como as questões circunjacentes ao arranjo produtivo local.

\section{Análise e Resgate de Depoimentos}

Na composição desta pesquisa, incluímos um espaço livre (free elicitation) para registro de opiniões quanto à visibilidade do ofício e produtos das bordadeiras. Neste estudo, o espaço aberto recebeu 17 (25\%) contribuições, um percentual adequado considerando a quantidade de participantes da pesquisa e o questionamento suscitado. 
No que se refere à "percepção social do ofício das bordadeiras", dez dos entrevistados (aproximadamente $90 \%$ ) utilizaram o espaço para falar do entusiasmo e da postura das mulheres empreendedoras para se associarem e lutarem num cenário de dificuldades. Alguns também "teceram" comentários sobre o momento político pouco convidativo a prospecções de cunho cultural, sem, no entanto, entrarem em maiores detalhes. A visão de sete $(40 \%)$ dos respondentes que utilizaram o espaço reservado (ofício) é a da mulher chefe de família e transmissora de saber, como mostram algumas expressões:

Vejo que a mulher daqui tem uma tradição que nasce na Europa; as mulheres aprendem cedo, e seu produto é destaque nessa região em conjunto com o petróleo, fé e valor considerável devido ao alto tempo despendido na confecção das peças, que são um sonho de rendar e fazer caixa.

Elas [bordadeiras] fazem com capricho e destreza; a renda é divina; suas mãos trazem um riscado secular; a renda é muito importante para cidade; mostra um elemento que identifica as mulheres e a igreja é adornada pelas rendas que as mulheres produzem. Elas ficam felizes por venderem e passarem a beleza [...].

Mais de 170 mulheres fazem essa renda irlandesa que é trabalho especializado, e mostra-me que as mulheres fazem algo único, diferencial, que tem títulos, e elas têm muitas conquistas, mostram que estão atualizadas, estudam, geram negócios e atuam com muito orgulho o valor da origem.

Os relatos carregam uma variedade de referências a respeito de possíveis "qualidades empreendedoras", além do legado de patrimônio histórico, cultural e imaterial do ofício dessas mulheres. Paralelamente, 11 dos 17 respondentes (aproximadamente 65\%) opinaram que as bordadeiras são gente com alta capacidade de transmissão de saber, e muito persistentes, como mostram os relatos a seguir:

Esse legado é das missionárias que passaram pela região, e a renda irlandesa é fonte de sustento. Verificamos que algo tão lindo veio de famílias de elites. Nas rendas usam técnicas de cordão sedoso, relevo e vivido. As firmes mulheres criam pontos diferentes e geram ensinamento, cidadania, encanto e paz.

As rendeiras aprendem com as mestras; os produtos são encomendados, e a comunidade pobre precisa preservar essa cultura. A riqueza de detalhes mostra a força de uma tradição. Elas, gente que são, fazem por amor, pois cada peça tem capricho e qualidade; todos admiram. Todos falam que foi bem-feita e isso mostra que essa gente tem pertencimento no lugar [...].

A divulgação [dos produtos] é essencial, pois elas [as mulheres] sabem fazer e deixam acumular para mostrar também que o bordado demanda tempo. Realmente, têm bordados que demoram anos para ficar pronto; tudo é uma questão de sutileza e pulso exato da líder familiar para conciliar outras tarefas. As bordadeiras colecionam conquista diversas, seja nas parcerias com a prefeitura, o Sebrae e algumas grifes e na constituição da associação. São muitos os aprendizados, como mostra o adquirido selo [indicação geográfica] de referência e status que foi conquistado por elas conjuntamente.

Destaca-se, ainda, que oito (47\%) participantes utilizam o espaço para ressaltar questões muito "específicas" da renda irlandesa, envolvendo a questão da educação, da transmissão de valores morais, respeito pelos anciãos, cidadania, sustentabilidade e a destreza das mãos, que são "divinas" na opinião deles. 


\section{CONSIDERAÇÕES E RECOMENDAÇÕES}

Retomamos que o objetivo principal foi avaliar as percepções e as expectativas dos compradores de renda irlandesa acerca dos serviços prestados pelas mulheres artesãs (bordadeiras) de Divina Pastora, região turística "Polo dos Tabuleiros" no leste sergipano. Os resultados apontam para a pertinência de se examinar o mapeamento das expectativas e das percepções da comunidade turística e traçar ações para sustentabilidade e processo de desenvolvimento de serviços das mulheres e meninas no município estudado por parte da administração pública, mas também das organizações privadas na região.

A visibilidade do trabalho das bordadeiras do município de Divina Pastora aparece em atributos de qualidade delineados pela Garantia e pela Confiabilidade. Os atributos assinalam um conjunto de habilidades, técnicas, conhecimentos e atitudes residentes numa economia de característica criativa, de impulso associativista. Os respondentes ressaltam a qualidade do artesanato produzido por essas mulheres, além de salientarem a utilidade e a criatividade no desenvolvimento de novas peças.

Assim, fica a imagem de uma mulher atuante, que tem destreza em ensinar e aprender, mãos que fazem "divinas" rendas com feição única, de extrema leveza e sedosidade, como demonstram as pessoas abordadas na pesquisa. Ressalta-se também, nesta pesquisa, que a integração dessa região faz com que o artesanato em renda irlandesa seja corresponsável pela ascensão social de muitas mulheres que deixaram o trabalho no campo para custearem os estudos, seus e de alguns de seus pares, a partir de sua produção e venda.

No que diz respeito à metodologia, a abordagem Servqual (gap model) mostrou-se apropriada para pontuar diretrizes da qualidade nesse tipo de empreendimento (Residenciais-Associativos). Das dimensões estudadas, ficaram evidentes as dimensões Garantia (gap de $|0,3|$ ) e Confiabilidade (gap de $|0,4|$ ) esferas que estão mais ajustadas ao ideal de qualidade do público consumidor/turístico entrevistado.

Pensa-se, no entanto, que merece uma investigação mais aprofunda sobre o porquê da dimensão Receptividade (gap de $|0,8|$ ) ter se destacado no gap model, apesar de que, em geral, apenas os percentuais acima de um ponto imprimem uma visão negativa ao serviço prestado. A Receptividade é uma determinante que compreende a "disposição de ajudar os clientes e fornecer serviços com presteza" (LAS CASAS, 2017, p. 67); cabe destacar, todavia, que a prontidão não é algo mais pertinente à produção, afinal existem peças que demandam muito tempo para serem produzidas e aprimoradas.

Ainda que esta pesquisa tenha desvelado conhecimentos consideráveis a respeito das lacunas da qualidade, outros ela derivou (ante a festividade local, os empreendimentos residenciais e o valor do associativismo para reconhecimento/visibilidade de bens/artefatos culturais, patrimoniais e históricos). Por exemplo, qual a percepção dessas mulheres de Divina Pastora acerca do modo de pensar dos visitantes que escolhem a região como ponto turístico? E no que se refere à arte e à religiosidade, que aproximações e diferenças direcionam a confecção da produção e da hospitalidade? Dito de outro modo, quem vem se inovando nas práticas artesanais e na geração de acolhimento e mútuo aprendizado? 
Espera-se que essas provações possam desvelar saberes sobre o problema pesquisado e gerar autoconhecimento nessas mulheres com vistas a ofertar um pouco mais de representatividade desse ofício, trabalho que se mostra promissor para a presente e futuras gerações. Que os exemplos dessas mulheres, como sugere um dos entrevistados, desencadeie cidadania, encanto e paz.

\section{REFERÊNCIAS}

BRASIL. Decreto no 8.892, de 27 de outubro de 2016. Cria a Comissão Nacional para os Objetivos de Desenvolvimento Sustentável. Brasília, 2016. Disponível em: www4.planalto.gov.br/ods/assuntos/legislacao. Acesso em: 1ㅇdez. 2016.

IBGE. Instituto Brasileiro de Geografia e Estatística. Cidades. 2017, 2010. Disponível em: https://cidades. ibge.gov.br/.

IPHAN. Instituto do Patrimônio Histórico e Artístico Nacional. Renda Irlandesa (SE): do risco de extinção à sustentabilidade. Brasília: IPHAN, 2018. Disponível em: http://portal.iphan.gov.br/noticias/detaIhes/4593. Acesso em: 8 jan. 2017.

LAS CASAS, A. L. Qualidade total em serviços: conceitos, exercícios, casos práticos. 6. ed. São Paulo: Atlas, 2017. 223p.

LIKERT, R. A technique for the measurement of attitudes. Archives of Psychology, n. 140, p. 44-53, 1932. MARTINS, É. S. M.; ALMEIDA, M. R. P. Ecoturismo, qualidade de vida e artesanato de renda irlandesa em Sergipe. ComCiência, Campinas, n. 119, 2010. Disponível em: http://comciencia.scielo.br/scielo.php?script=sci_arttext\&pid=S1519-76542010000500012\&lng=pt\&nrm=iso. Acesso em: 11 jul. 2017.

MASCELANI, A. Caminhos da arte popular: o Vale do Jequitinhonha. Rio de Janeiro: Museu Casa do Pontal, 2008. 179p.

MAUSS, M. Sociologia e antropologia. São Paulo: Cosac \& Naify, 2003.

MELLO, J.; SILVA, E. P. Artesanato de renda irlandesa em Sergipe: histórias de vida, histórias de ofício. História, histórias, v. 2, n. 4, p. 131-148, 2014. Disponível em: http://periodicos.unb.br/ojs311/index.php/ hh/article/view/10814. Acesso em: 21 fev. 2017.

MIGUEL, M. C.; FREIRE, V. F. Avaliação da qualidade orientada ao usuário do Museu Capixaba do Negro: aplicação da abordagem teórico-metodológica Servqual em um espaço museológico de Vitória-ES. Guará, Vitória, v. 5, n. 1, p. 103-116, 2016. Disponível em: http://periodicos.ufes.br/guara/article/ view/14350/10092. Acesso em: 28 fev. 2017.

NITECKI, D. A.; HERNON, P. Measuring service quality at Yale's University's libraries. Journal of Academic Librarianship, v. 26, n. 4, p. 259-273, 2000.

ONU. Organização das Nações Unidas. Financiamento transformador. Disponível em: www.onumulheres. org.br/noticias/financiamento-transformador-pode-acabar-com-a-desigualdade-de-genero-ate-2030/. Acesso em: 18 abr. 2017.

OURIQUES, H. R.; RAMOS, I. S. Trabalho feminino no Terceiro Setor: o mito da emancipação feminina. In: PIMENTA, S. M.; SARAIVA, L. A. S.; CORRÊA, M. L. (org.). Terceiro setor: dilemas e polêmicas. São Paulo: Saraiva, 2006. p. 137-162.

PARASURAMAN, A.; ZEITHAML, V. A.; BERRY, L. L. A conceptual model of service quality and its implications for future research. Journal of Marketing, Chicago, v. 49, n. 4, p. 41-50, 1985.

POSSAMAI, Z. R. O lugar do patrimônio na operação historiográfica e o lugar da história no campo do patrimônio. Anos 90: Revista do Programa de Pós-Graduação em História da Universidade Federal do Rio Grande do Sul, v. 25, n. 48, p. 23-49, 2018. Disponível em: https://seer.ufrgs.br/anos90/article/ view/83688/51158. Acesso em: 15 dez. 2018.

SOARES, S. M. Onde há rede, há renda: técnica e gênero em Raposa-MA. 2011. 117f., il. Dissertação (Mestrado em Antropologia Social) - Universidade de Brasília, Brasília, 2011. Disponível em: http://www.dan. unb.br/images/doc/Dissertacao_271.pdf. Acesso em: 15 jan. 2017.

VIEIRA, K. M.; DALMORO, M. Dilemas na construção de escalas Tipo Likert: o número de itens e a disposição influenciam nos resultados? In: ENANPAD, 32., 2008, Rio de Janeiro. Anais [...]. Rio de Janeiro, set. 2008.

WEBER, M. A ética protestante e o "espírito" do capitalismo. São Paulo: Companhia das Letras, 2004. $335 \mathrm{p}$.

ZACCHI, M. S.; FIGUEIREDO, W. (org.). Divina pastora: caminhos da renda irlandesa. Rio de Janeiro, RJ: Centro Nacional de Folclore e Cultura Popular; IPHAN, 2013. 161p. 